\title{
Detection of pleural plaques in workers exposed to inhalation of natural fluoro-edenite fibres
}

\author{
VENERANDO RAPISARDA ${ }^{1 *}$, CATERINA LEDDA ${ }^{2 *}$, VINCENZO RICCERI $^{3}$, \\ FRANCESCO ARENA ${ }^{4}$, ANDREA MUSUMECI ${ }^{4}$, ANDREA MARCONI ${ }^{1}$, LUCREZIA FAGO $^{1}$, \\ MASSIMO BRACCI ${ }^{5}$, LORY SANTARELLI ${ }^{5}$ and MARGHERITA FERRANTE ${ }^{2}$ \\ ${ }^{1}$ Division of Occupational Medicine, 'Policlinico-Vittorio Emanuele' University Hospital; \\ ${ }^{2}$ Hygiene and Public Health, Department of G.F. Ingrassia, University of Catania, Catania 8795123; \\ ${ }^{3}$ Division of Radiology, Hospital Maria Santissima Addolorata - Biancavilla, Provincial Health Unit Catania, \\ Biancavilla 195033; ${ }^{4}$ Division of Radiology, 'Policlinico-Vittorio Emanuele' University Hospital, \\ University of Catania, Catania 7895123; ${ }^{5}$ Occupational Medicine, Department of Clinical and \\ Molecular Sciences, Marche Polytechnic University, Torrette, Ancona 60020, Italy
}

Received March 19, 2014; Accepted December 3, 2014

DOI: $10.3892 / \mathrm{ol} .2015 .2978$

\begin{abstract}
Fluoro-edenite is a natural mineral species initially isolated in Biancavilla, Sicily. The fibres are similar in size and morphology to certain amphibolic asbestos fibres, the inhalation of which may cause chronic inflammation and cancer. Occupational asbestos exposure is known to be associated with pleural and lung diseases, including pleural plaques. The aim of this study was to report the pleural and lung parenchymal lesions detected by high-resolution computed tomography (HRCT) in a group of construction workers exposed to fluoro-edenite. Information regarding life habits and occupational history was collected from 43 workers enrolled into the study. The participants underwent physical examination, blood analysis, search for uncoated fibres and ferruginous bodies in the sputum, pulmonary function tests, including diffusion capacity for carbon monoxide $\left(\mathrm{TL}_{\mathrm{CO}}\right)$, and HRCT chest imaging. A general descriptive outcome analysis was also conducted; a prevalence ratio (PR) with 95\% confidence interval and a two-tailed test P-value were calculated for pleural plaques using log-binomial regression, measuring plaque size and thickness, and cumulative exposure index (CEI). The mean values of the functional respiratory tests were within the normal range for all participants. A restrictive ventilatory defect was identified in two (5\%) subjects and an
\end{abstract}

Correspondence to: Dr Caterina Ledda, Hygiene and Public Health, Department of G.F. Ingrassia, University of Catania, Via Santa Sofia, Catania 8795123, Italy

E-mail: cledda@unict.it

*Contributed equally

Key words: pleural plaques, Biancavilla, Sicily, fibres, asbestos, occupational exposure, construction workers obstructive ventilatory defect in three $(7 \%)$ subjects. $\mathrm{TL}_{\mathrm{CO}}$ was reduced in two additional participants. Fibres were detected in $19(44 \%)$ of subjects. Pleural involvement was documented in $39(91 \%)$ workers, of whom $31(72 \%)$ had bilateral plaques. Calcifications were detected in 25 (58\%) of these participants. $\mathrm{PR}$ indicated a progressive increase in the risk of developing pleural lesions with rising CEI, i.e. length of exposure. The present findings demonstrate for the first time the presence of pleural plaques in the lungs of subjects exposed to fluoro-edenite fibres, and not to asbestos, through residing in Biancavilla and through their occupation.

\section{Introduction}

In the late 1990s, a greatly increased standardised rate of mortality from pleural mesothelioma was highlighted by epidemiological surveys in the area of Biancavilla, a Sicilian town on the south west slope of Mount Etna volcano $(1,2)$. Subsequent studies identified an asbestiform mineral fibre in the benmoreitic lava from a local stone quarry. The quarry had been mined from 1950-1998 to extract sand and gravel, which was routinely used by builders to produce pavements and house plaster $(2,3)$. The fibre was identified as fluoro-edenite (4).

Fluoro-edenite $\left(\mathrm{NaCa}_{2} \mathrm{Mg}_{5} \mathrm{Si}_{7} \mathrm{AlO}_{22} \mathrm{~F}_{2}\right)$ is a new mineral species recognised by the Commission on New Minerals and Mineral Names (CNMMN; IMA: code 2000-049) in 2001 (5). The fibres are similar in size and morphology to certain amphibolic asbestos fibres (including tremolite, actinolite and antophyllite) (4), the inhalation of which may cause chronic inflammation and pleural mesothelioma $(1,2)$.

Based on previous animal studies, long, thin asbestos fibers ( $\geq 8 \mu \mathrm{m}$ in length and $\leq 0.25 \mu \mathrm{m}$ in width) have been postulated to be strongly carcinogenic; inducing pleural malignant mesothelioma, while shorter, thicker fibers are thought to pose a smaller risk (6). The relationship between asbestos exposure and respiratory disease has been studied extensively (7). Occupational exposure to asbestos is known to be associated with 
pleural and lung diseases, including pleural plaques, pleurisy, fibrosis of the visceral pleura, rounded atelectasis, asbestosis, lung cancer and malignant mesothelioma (8). These diseases, termed asbestos-related diseases, are well documented and approximately 107,000 mortalities are attributable to asbestos exposure worldwide, annually $(9,10)$. Little has been established with regard to the effects of human exposure to fluoro-edenite fibres (11-13), however, epidemiological studies have indicated that these fibres may have a causative role in chronic obstructive lung disease $(1,14)$ and malignant pleural mesothelioma $(2,14)$.

The aim of the current study was to evaluate the findings following the assessment of the pleura and lung parenchyma of a group of construction workers residing and working in the area of Biancavilla.

\section{Materials and methods}

Subjects. Between 2009 and 2013, 52 male construction workers living and working in the area of Biancavilla were visited within the framework of periodic occupational surveillance and invited to participate in this study. A free medical examination, including a high-resolution computer tomography (HRCT) chest scan, was offered to participants.

Exclusion criteria were broncho-pulmonary diseases (e.g. asthma, bronchopneumonia, and tuberculosis), previous asbestos exposure, and involvement in construction work in the Biancavilla area for $<1$ year.

A questionnaire was used to collect information about the participants with regard to family, medical history, medication, drinking habits, hobbies, etc. Questions on tobacco consumption enabled participants to be classified as current smokers, ex-smokers (those who had not smoked for $>1$ year) and non-smokers (those who had never smoked).

The research protocol was approved by the Ethics Committee of Catania University Hospital (Catania, Italy) and the written informed consent of all subjects was acquired prior to their inclusion in the study.

Fluoro-edenite exposure. The questionnaire was used to determine fluoro-edenite exposure based on each participant's occupational history. Duration (years) and dates of exposure were recorded. The intensity of exposure was weighted according to occupation, as follows: Low (electricians) (passive), 0.01; low intermediate (tilers, crane operators), 0.1 ; high intermediate (painter, shovel operator), 1 ; high (carpenter, plasterer, plumber), 10. A cumulative exposure index (CEI) to fluoro-edenite was calculated for each subject as the sum of all periods of employment in jobs involving exposure (duration $\mathrm{x}$ weighting factor). Due to a lack of data regarding air-borne fibres, and of detailed information on exposure frequency (percentage working time), the CEI was expressed as exposure unit $x$ year rather than as fibres/ml $\mathrm{x}$ year. Latency was defined as the interval from the beginning of the first job considered to entail fluoro-edenite exposure, to the date of the HRCT scan performed in the present study.

Clinical parameters. On acquiring a detailed case history, workers were subjected to: i) Physical examination; ii) blood analysis; iii) search for uncoated fibres and ferruginous bodies in sputum; iv) pulmonary function tests and diffusion capacity for carbon monoxide $\left(\mathrm{TL}_{\mathrm{CO}}\right)$; and v) HRCT chest scanning. Respiratory symptoms were graded using the American Thoracic Society (ATS) questionnaire (15).

Venous blood $(10 \mathrm{ml})$ was collected in the morning, following overnight fasting, to determine red blood cell count, haematocrit, haemoglobin levels, white blood cell count, erythrocyte sedimentation rate, C-reactive protein levels and liver enzyme (aspartate aminotransferase and alanine aminotransferase) levels.

Sampling and fibre search were conducted according to the protocol by Putzu et al (16). Sputum was classified as negative or positive for uncoated fibres and ferruginous bodies (detection limit, $120 \mathrm{ppm}$ ).

Respiratory function tests were conducted using a bell spirometer (Biomedin, Padova, Italy) (17). Equipment, calibration and manoeuvres met ATS guidelines (15). Forced vital capacity, forced expiratory volume in $1 \mathrm{~s}$, peak expiratory flow, maximal expiratory flow rate at $25-75 \%$ of the vital capacity, total lung capacity, and $\mathrm{TL}_{\mathrm{CO}}$ were measured and expressed as a proportion of European Coal and Steel Community reference values adjusted for individual characteristics (age, weight and height) recorded at the time of testing (18).

Subjects underwent HRCT scanning with the use of an Optima CT 580W (GE Healthcare, Fairfield, CT, USA), without contrast enhancement, according to a specifically devised protocol: The entire chest was screened using spiral acquisition sequences with the subject in supine position. Interstitial or pleural abnormalities were recorded in standardised form using the Fleischner Society glossary of terms (16). Pleural plaques were defined as circumscribed quadrangular elevations with sharp borders and density comparable to tissue, with/without signs of calcification. Thickness was classified, based on the thickest plaque, into four categories ( $<2 \mathrm{~mm}, 2-<5 \mathrm{~mm}, 5-<10 \mathrm{~mm}$ and $\geq 10 \mathrm{~mm}$ ). Cut-off criteria were selected and adapted from the International Labour Office classification of radiographs of pneumoconiosis (16).

Parenchymal abnormalities (subpleural dependent opacity, subpleural curvilinear opacities, subpleaural perpendicular lines, parenchymal nodules, honeycombing and ground glass opacities) were recorded and classified by three chest radiologists using a semiquantitative 10-class scale including six subclasses; 0 (no finding), 1 (normal), 2 (subnormal; one or two abnormalities located sporadically in the lung periphery, no honeycombing), 3 (mild fibrosis; at least two abnormalities located on both sides and in several slices from the lung periphery, no honeycombing), 4 (moderate fibrosis; several criteria, which extend deeper into the lung, honeycombing as a general rule), 5 (severe fibrosis; several abnormalities or associated findings extending deep into the lung, honeycombing, lung architectural change) and 6 (extreme fibrosis; extremely severe and various fribrotic changes, little normally aerated lung remaining) as previously described by Gangemi et al (17).

Statistical analysis. Data analysis was performed using SPSS software version 20 (IBM, Milan, Italy). The main population characteristics, respiratory test results and characteristics of the pleural plaques were expressed as 
Table I. Characteristics of the study population of exposed workers $(n=43)$.

Patient characteristics

Participants

Age, mean $\pm \mathrm{SD}$, years

$49.3 \pm 6.7$

Occupation, $\mathrm{n}(\%)$

Unskilled construction worker

$16(37)$

Specialised construction worker

Carpenters

Duration of residence in Biancavilla, mean \pm SD, years

Smoking habits, n (\%)

Current smokers ${ }^{\mathrm{a}}$

Ex-smokers ${ }^{\text {a }}$

Non-smokers ${ }^{\mathrm{a}}$

CEI to fluoro-edenite (exposure unit x years), $\mathrm{n}(\%)$

$$
1-9
$$

10-19

20-29

$30-39$

$\geq 40$

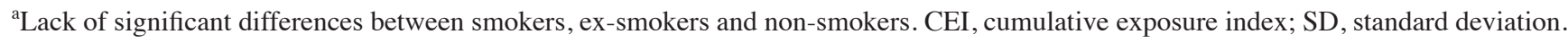

Table II. Results of respiratory tests (expressed as \% predicted mean \pm SD) and sputum examination (expressed as $\mathrm{n}$ and $\%$ ) of participants, subdivided by occupational CEI values.

\begin{tabular}{|c|c|c|c|c|c|}
\hline CEI & $1-9$ & $10-19$ & $20-29$ & $30-39$ & $\geq 40$ \\
\hline Subjects, n $(\%$ a) & $2(5)$ & $9(21)$ & $23(53)$ & $7(16)$ & $2(5)$ \\
\hline Smokers, n $\left(\%^{\mathrm{b}}\right)$ & $3(23)$ & $4(31)$ & $3(23)$ & $2(15)$ & $1(8)$ \\
\hline $\mathrm{FVC}, \%$ & $98.2 \pm 5.7$ & $97.7 \pm 1.1$ & $96.9 \pm 1.6$ & $92.9 \pm 6.7$ & $90.8 \pm 8.6$ \\
\hline $\mathrm{FEV}_{1}, \%$ & $98.8 \pm 7.8$ & $95.5 \pm 1.3$ & $93.6 \pm 1.4$ & $87.6 \pm 6.5$ & $83.3 \pm 9.1$ \\
\hline PEF, \% & $97.6 \pm 7.9$ & $95.2 \pm 6.4$ & $92.3 \pm 5.7$ & $90.7 \pm 6.9$ & $86.9 \pm 9.6$ \\
\hline $\mathrm{MEF}_{25-75}, \%$ & $94.5 \pm 8.6$ & $94.3 \pm 9.1$ & $89.5 \pm 6.3$ & $85.2 \pm 6.1$ & $82.5 \pm 8.7$ \\
\hline TLC,$\%$ & $96.6 \pm 5.6$ & $95.5 \pm 3.3$ & $90.3 \pm 7.2$ & $88.9 \pm 5.1$ & $87.7 \pm 5.4$ \\
\hline $\mathrm{TL}_{\mathrm{CO}}, \%$ & $96.9 \pm 6.4$ & $95.4 \pm 6.6$ & $90.2 \pm 4.1$ & $81.5 \pm 5.7$ & $79.3 \pm 6.4$ \\
\hline Fibres present in sputum, $\mathrm{n}\left(\%^{\mathrm{c}}\right)$ & $0(0)$ & $4(21)$ & $12(63)$ & $2(11)$ & $1(5)$ \\
\hline
\end{tabular}

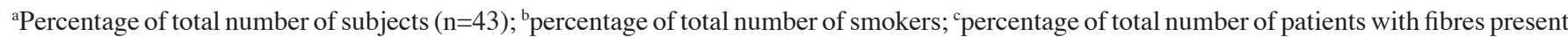
in sputum ( $\mathrm{n}=19)$. CEI, cumulative exposure index; $\mathrm{FVC}$, forced vital capacity; $\mathrm{FEV}_{1}$, forced expiratory volume in $1 \mathrm{~s} ; \mathrm{PEF}$, peak expiratory flow; $\mathrm{MEF}_{25-75}$, maximal expiratory flow rate at $25-75 \%$ of the vital capacity; TLC, total lung capacity; $\mathrm{TL}_{\mathrm{CO}}$, diffusion capacity for carbon monoxide.

the mean \pm standard deviation (SD) or as the total number of participants with that characteristic and the percentage represented by that number. The variables used to determine fluoro-edenite exposure were exposure duration, CEI, and the interval between earliest exposure and the HRCT scan conducted during the present study.

A prevalence ratio (PR) with $95 \%$ confidence interval $(\mathrm{CI})$ and two-tailed test P-value were calculated for pleural plaques using log-binomial regression, measuring plaque size and thickness, and CEI. Potential confounders were identified from the literature and included in the analysis; the confounding factors used in the models were age and smoking status. Age was modeled as a continuous variable while smoking status was dichotomised as smoker and ex-smoker versus non-smoker.

\section{Results}

Application of the exclusion criteria led to the exclusion of nine subjects, due to previous exposure to asbestos $(n=5)$, bronchopneumonia $(n=2)$, tuberculosis $(n=1)$ or allergic bronchial asthma $(n=1)$, leaving 43 participants, whose characteristics are reported in Table I. All 43 workers included in the study had been residing in Biancavilla for $>40$ years, and $65 \%(n=28)$ were born there. Additionally, all had been working almost exclusively in and around Biancavilla. The 
Table III. High-resolution computed tomography findings in the lung parenchyma of 43 workers.

Subjects with unilateral abnormalities, $\mathrm{n}(\%$; mean score $\pm \mathrm{SD})$
Subjects with bilateral abnormalities, $\mathrm{n}(\%$; mean score $\pm \mathrm{SD})$

$\begin{array}{lcc}\text { Rounded atelectasis } & 2(5 \% ; 1.12 \pm 0.23) & 0 \\ \text { Emphysema } & 0 & 0 \\ \text { Thickness } & 0 & 0 \\ \text { Bronchiectasis } & 0 & 5(12 \% ; 2.07 \pm 0.65) \\ \text { Fibrosis } & 2(5 \% ; 1.43 \pm 0.32) & 5\end{array}$
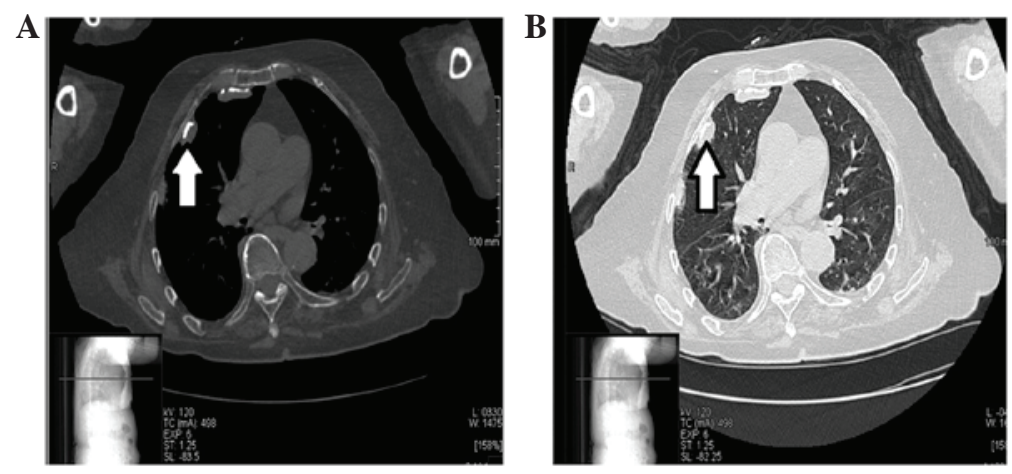

Figure 1. High-resolution computed tomography imaging demonstrated partially calcified pleural plaques in the left parietal pleura (arrow). (A) View of the mediastinum, (B) view of the parenchyma.
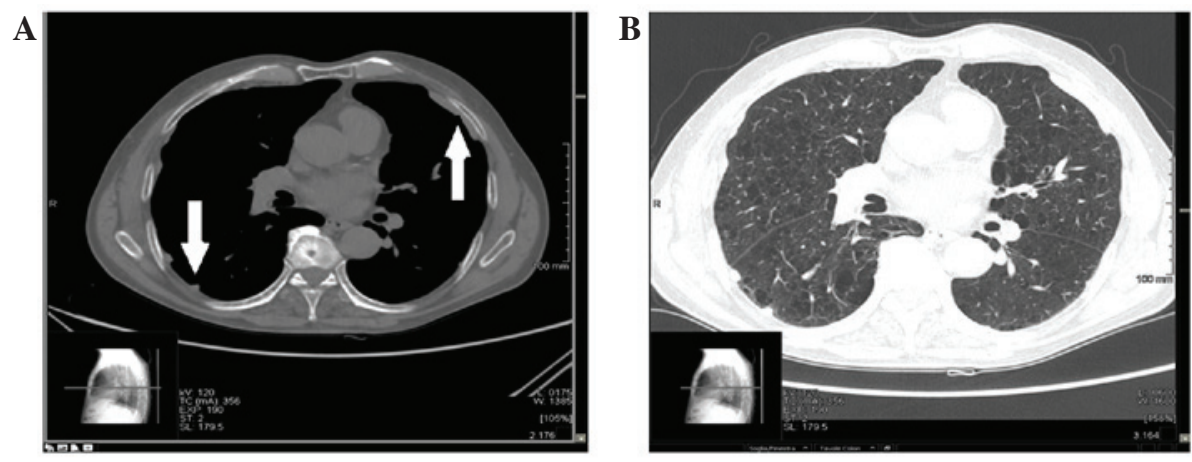

Figure 2. Non-enhanced high-resolution computed tomography images. (A) View of the mediastinum, (B) view of the parenchyma. Unilateral calcified pleural plaques $\sim 1 \mathrm{~cm}$ in thickness at the level of the right parietal pleura (arrows) coexist with lung interstitial abnormalities and diffuse lobular septal thickening. The parietal pleura is thickened bilaterally; on the right the pleura is thickened and lobulated in the absence of evident plaque calcification.

occupational history recorded from the participants revealed that $38(88 \%)$ had personally handled and mixed gravel from the Mount Calvario quarry until 1998. Furthermore, all had been involved in restoring houses that had been built in the 1950s, when lava from the quarry had been extensively used as a building material. Smokers, ex-smokers and non-smokers did not differ significantly with regard to any study parameter.

A CEI ranging from 10-29 was determined in the majority of participants $(\mathrm{n}=30 ; 70 \%)$. Respiratory symptoms were identified in six (14\%) workers: Four (10\%) had a cough and two (5\%) had mild (grade I) dyspnoea. Other identified conditions not involving the respiratory apparatus were: Arterial hypertension $(n=5 ; 12 \%)$, type II diabetes mellitus $(n=2 ; 5 \%)$, dyslipidaemia $(\mathrm{n}=4 ; 10 \%)$, dysthyroidism $(\mathrm{n}=3 ; 7 \%)$ and prostatic hypertrophy $(\mathrm{n}=1 ; 2 \%)$. All conditions were being treated. Blood examination to determine red blood cell count, haematocrit, haemoglobin levels, white blood cell count, erythrocyte sedimentation rate, C-reactive protein levels and liver enzyme (aspartate aminotransferase and alanine aminotransferase) levels revealed that two participants (the two diabetic subjects) had hyperglycaemia (blood glucose level, $>125 \mathrm{mg} / \mathrm{dl}$ ); the parameters of the other workers were within the normal range.

The results from the respiratory tests and the search for uncoated fibres and ferruginous bodies in sputum are reported in Table II. The mean values (\% predicted) of the functional respiratory tests were within the normal range for all participants. A restrictive ventilatory defect was discovered in two (5\%) subjects and an obstructive 
Table IV. Characteristics of the pleural plaques detected by high-resolution computed tomography in 39 participants.

\begin{tabular}{|c|c|c|c|}
\hline Plaque features & Unilateral plaques, $\mathrm{n}\left(\%^{\mathrm{a}}\right)$ & Bilateral plaques, n $\left(\%^{\mathrm{b}}\right)$ & Total, $\mathrm{n}\left(\%^{\mathrm{c}}\right)$ \\
\hline \multicolumn{4}{|l|}{ Thickness, mm } \\
\hline$<2$ & $0(0 \%)$ & $5(16 \%)$ & $5(13 \%)$ \\
\hline $2-4.9$ & $5(62 \%)$ & $10(32 \%)$ & $15(38 \%)$ \\
\hline $5-9.9$ & $3(38 \%)$ & $9(29 \%)$ & $12(31 \%)$ \\
\hline$\geq 10$ & $0(0 \%)$ & $7(23 \%)$ & $7(18 \%)$ \\
\hline \multicolumn{4}{|l|}{ Size } \\
\hline$<1 \mathrm{~cm}$ & $0(0 \%)$ & $4(15 \%)$ & $4(10 \%)$ \\
\hline $1 \mathrm{~cm}-24 \%$ of lateral chest wall & $4(50 \%)$ & $15(48 \%)$ & $22(49 \%)$ \\
\hline $24-49 \%$ of lateral chest wall & $4(50 \%)$ & $9(29 \%)$ & $14(33 \%)$ \\
\hline$\geq 0 \%$ of lateral chest wall & $0(0 \%)$ & $3(10 \%)$ & $3(8 \%)$ \\
\hline Calcification & $4(50 \%)$ & $21(54 \%)$ & $25(58 \%)$ \\
\hline
\end{tabular}

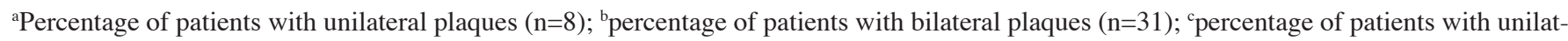
eral or bilateral plaques $(n=39)$.

Table V. PR with 95\% CI and two-tailed test P-value were calculated for the pleural plaques in the 39 (91\%) participants using log-binomial regression taking into consideration plaque size and thickness and CEI.

\begin{tabular}{lccr}
\hline & \multicolumn{3}{c}{ Risk indicators } \\
\cline { 2 - 4 } CEI to fluoro-edenite $^{\mathrm{a}}$ & PR & CI & P-value \\
\hline $1-9$ & 1.00 & & $>0.05$ \\
$10-19$ & 1.45 & $1.12-1.78$ & $>0.001$ \\
$20-29$ & 1.98 & $1.84-2.12$ & $>0.001$ \\
$30-39$ & 2.36 & $2.01-2.58$ & $>0.001$ \\
$\geq 40$ & 3.32 & $3.24-3.48$ & \\
\hline
\end{tabular}

${ }^{\text {a} E x p o s u r e ~ u n i t ~ x ~ y e a r s . ~ P R, ~ p r e v a l e n c e ~ r a t i o ; ~ C I, ~ c o n f i d e n c e ~ i n t e r v a l ; ~ C E I, ~ c u m u l a t i v e ~ e x p o s u r e ~ i n d e x . ~}$

ventilatory defect observed in three $(7 \%)$. $\mathrm{TL}_{\mathrm{CO}}$ was reduced in two additional participants. Overall, a slight non-significant reduction in predictive values (\%) was noted with rising CEI (range, 30- $\geq 40$ ). Fluoro-edenite fibres, but not fibre bundles, were recovered from the sputum of 19 (44\%) workers. The length of the fibres ranged from 10-35 $\mu \mathrm{m}$, with a diameter of $<0.5 \mu \mathrm{m}$. Ferruginous bodies were not identified in any of the samples.

The HRCT findings in lung parenchyma are reported in Table III. HRCT scans revealed low-grade fibrosis in seven workers (two unilateral and five bilateral) and unilateral rounded atelectasis in two workers. Pleural involvement was documented in 39 (91\%) subjects, of whom 31 (72\%) had bilateral plaques. Calcifications were detected in $25(58 \%)$ participants (Table IV). Examples of HRCT scans acquired from these participants are shown in Figs. 1 and 2. Calculation of plaque PR with 95\% CI, and the P-value from the two-tailed test by log-binomial regression, demonstrated a progressive increase in the risk of developing pleural lesions with rising CEI, i.e. length of exposure (Table V).

\section{Discussion}

Exposure to asbestiform fibres similar to that described in Biancavilla has been reported for erionite in the central Anatolian villages of Karain and Tuzkoy (21-23). Erionite is a fibrous zeolite found in the natural rock material used locally for building $(24,25)$. As in Biancavilla, a high mortality rate from pleural carcinoma (sentinel event) allowed for the recognition of population exposure and, consequently, occupational exposure, particularly for construction workers.

For decades, fluoro-edenite has been considered predominantly as a synthetic fibre (26-28). The natural environments from which it had previously been discovered include the Pargas region in Finland (29), the Utah Rocky Mountains (30) and the Orange area in New Jersey (31). However, Biancavilla is the first and sole instance involving human exposure $(2,3)$. Additionally, the fibres recovered from the lava of the Kimpo volcano in Kumamoto Prefecture (Japan) are structurally similar to Biancavilla's fluoro-edenite (32), 
however, they have never been submitted to the CNMMN, nor has human exposure been described.

The type of environmental contamination discovered in Biancavilla $(22,33,34)$ suggests that the entire population is exposed to fluoro-edenite (1). Construction workers are at increased risk due to additional exposure to fibres present in the cement and plaster made with contaminated material from the Mount Calvario quarry $(2,3)$.

The respiratory function tests and HRCT imaging conducted in the present study enabled the evaluation of the effects of fluoro-edenite fibres on subjects who are both residents and occupationally exposed subjects. The results document a broad involvement of the respiratory apparatus, and a greater involvement of the pleura (39/43) compared with the lung. However, these lesions have a limited effect on respiratory function, as has been demonstrated from the results of the spirometry. The respiratory function data collected in the present study are consistent with those of other studies conducted on construction workers with pleural plaques related to occupational asbestos exposure (35-38).

Pleural plaques are circumscribed, thickened areas, consisting of avascular connective tissue, localised to the parietal and/or diaphragmatic pleura of asbestos-exposed subjects (38). They may reflect a local (pleural) response to asbestos fibre accumulation, and are typically detected in exposed construction workers (39). Plaques indicate consistent exposure to low fibre concentrations (0.19 fibre-years/ml) (40). Other potential pleural responses include lymph node calcification and carcinogenesis $(41,42)$. The results of the current study are consistent with those of other studies, which reported that, in cases of chest wall pleural plaques detected in asbestos-exposed construction workers, $70 \%$ exhibit lesions on both sides of the chest $(20,39,43)$, and $\sim 30 \%$ also exhibit calcifications ( $25 \%$ in the current sample) $(20,39)$.

Subjects with pleural plaques are at greater risk of lung cancer and malignant pleural mesothelioma, compared with the general population $(38,41,42,44)$. Inhalation of asbestos fibres may induce two types of interconnected pathogenic processes involving the respiratory apparatus: Chronic inflammation or carcinogenesis. These effects are related to the ability of fibres to disrupt mitotic mechanisms, stimulate host cell proliferation, induce release of free radicals (resulting in DNA damage), and prolong the release of cytokines and growth factors $(45,46)$. In vivo and in vitro analysis of the biological reactivity of fluoro-edenite fibres has also demonstrated that they are able to cause the production of reactive oxygen species, stimulation of the intrinsic and extrinsic apoptosis pathways, and induction of inflammatory processes through the activation of specific cytokines (47-51).

With regard to the recovery of fibres from sputum, the current data are consistent with those of Putzu et al (16), who described fibres similar to those found in the present study in $50 \%(6 / 12)$ of their sample of Biancavilla residents (vs. 44\%, or $19 / 43$, in the current study). That these subjects were four housewives, a farmer and a mason, with no history of exposure to fluoro-edenite fibres, indicates a predominantly environmental exposure.

Environmental contamination had previously been demonstrated by examination of the lungs and lymph nodes of sheep whose pastures lay a few kilometres from Biancavilla $(33,34)$.
Therefore the risk of inhalation of dust particles, particularly fluoro-edenite fibres, from Mount Calvario quarry is high even in open, non-urban areas located a short distance away from this region $(33,34)$. Such contamination is likely to be the cause of the pleural plaques detected in the lungs of the construction workers in the current study with a relatively short occupational exposure (low CEI). The significantly greater plaque size and thickness observed in workers with a higher CEI may indicate a combination of environmental and occupational exposure, thus increasing the risk of development of respiratory conditions in these individuals (52).

A form of biphasic pollution may be hypothesised for fluoro-edenite, as proposed for asbestos fibres (53). As sand from the Mount Calvario quarry is commonly used locally in the production of building materials, the maintenance, repair and restructuring work conducted over the years may have induced the fragmentation of larger particles and fibres into smaller particles and fibres, capable of remaining airborne for a long period, and of disseminating over considerable distances.

The present findings demonstrate for the first time pleural plaques in the lungs of subjects not exposed to asbestos, but to fluoro-edenite fibres, through living and working in Biancavilla. The data indicate the requirement to establish a population screening programme for conditions associated with fibre exposure. All sources of occupational exposure to fluoro-edenite fibres must be identified and measures should be taken to minimise this exposure, including periodic environmental fibre monitoring and adaptation of a surveillance protocol to consider the health effects of fibres, assess risks and calculate the cost-benefit ratio of the monitoring programme.

The present, preliminary study is of value as it describes pleural plaques that may be ascribed to exposure to fluoro-edenite fibres. Investigation of the resident population and of larger cohorts of exposed workers is required to gain further insights.

\section{Acknowledgements}

The authors would like to thank Dr Marine Castaing (Cancer Registry of Catania-Messina-Siracusa-Enna; University of Catania, Catania, Italy) for her assistance and support.

\section{References}

1. Di Paola M, Mastrantonio M and Carboni M: Mortality from malignant pleural neoplasms in Italy in the years 1988-1992. Rapporti ISTISAN 96/40. Rome, Italy, pp1-30, 1996.

2. Paoletti L, Batisti D, Bruno C, et al: Unusually high incidence of malignant pleural mesothelioma in a town of eastern Sicily: an epidemiological and environmental study. Arch Environ Health 55: 392-398, 2000.

3. Rapisarda V, Amati M, Coloccini S, et al: The in vitro release of hydroxyl radicals from dust containing fluoro-edenite fibers identified in the volcanic rocks of Biancavilla (eastern Sicily). Med Lav 94: 200-206, 2003 (In Italian)

4. Comba P, Gianfagna A and Paoletti L: Pleural mesothelioma cases in Biancavilla are related to a new fluoro-edenite fibrous amphibole. Arch Environ Health 58: 229-232, 2003.

5. Gianfagna A and Oberti R: Fluoro-edenite from Biancavilla (Catania, Sicily, Italy): Crystal chemistry of a new amphibole end-member. Am Mineral 86: 1489-1493, 2001.

6. Stanton MF, Layard M, Tegeris A, et al: Relation of particles dimension to carcinogenicity in amphibole asbestoses and fibrous minerals. J Natl Cancer Inst 67: 965-975, 1981.

7. Bernstein D, Dunnigan J, Hesterberg T, et al: Health risk of chrysotile revisited. Crit Rev Toxicol 43: 154-183, 2003. 
8. Becklake MR, Bagatin E and Neder JA: Asbestos-related diseases of the lungs and pleura: uses, trends and management over the last century. Int J Tuberc Lung Dis 11: 356-69, 2007.

9. Robinson BW and Lake RA: Advances in malignant mesothelioma. N Engl J Med 353: 1591-1603, 2005.

10. World Health Organization: Asbestos: elimination of asbestos-related diseases. http://www.who.int/mediacentre/factsheets/fs343/en/. Accessed January 20, 2015.

11. Fazzo L, Minelli G, De Santis M, et al: Mesothelioma mortality surveillance and asbestos exposure tracking in Italy. Ann Ist Super Sanita 48: 300-310, 2012.

12. Loreto C, Carnazza ML, Cardile V, et al: Mineral fiber-mediated activation of phosphoinositide-specific phospholipase $\mathrm{c}$ in human bronchoalveolar carcinoma-derived alveolar epithelial A549 cells. Int J Oncol 34: 371-376, 2009.

13. Musumeci G, Loreto C, Cardile V, et al: Immunohistochemical expression of retinoblastoma and phospho-retinoblastoma protein in sheep lung exposed to fluoro-edenite fibers. Anat $\mathrm{Sci}$ Int 85: 74-78, 2010.

14. Biggeri A, Pasetto R, Belli S, et al: Mortality from chronic obstructive pulmonary disease and pleural mesothelioma in an area contaminated by natural fiber (fluoro-edenite). Scand J Work Environ Health 30: 249-252, 2004.

15. Standards for the diagnosis and care of patients with chronic obstructive pulmonary disease. American Thoracic Society. Am J Respir Crit Care Med 152: S77-S121, 1995.

16. Putzu MG, Bruno C, Zona A, et al: Fluoro-edenitic fibres in the sputum of subjects from Biancavilla (Sicily): a pilot study. Environ Health 5: 20, 2006.

17. Gangemi S, Rapisarda V, Minciullo PL, et al: Circulating levels of interleukin-18 in asbestos-exposed workers. Toxicol Ind Health 21: 125-129, 2005.

18. Miller MR, Hankinson J, Brusasco V, et al: Standardisation of spirometry. Eur Respir J 26: 319-338, 2005.

19. Hansell DM, Bankier AA, MacMahon H, et al: Fleischner Society: glossary of terms for thoracic imaging. Radiology 246 697-722, 2008

20. International Labour Organization: ILO standards-related activities in the area of occupational safety and health: An in-depth study for discussion with a view to the elaboration of a plan of action for such activities. Report VI. Geneva, International Labour Office, 2003.

21. Baris B, Demir AU, Shehu V, et al: Environmental fibrous zeolite (erionite) exposure and malignant tumors other than mesothelioma. J Environ Pathol Toxicol Oncol 15: 183-189, 1996.

22. Temel A and Gündoğdu MN: Zeolite occurrences and the erionite-mesothelioma relationship in Cappadocia, central Anatolia, Turkey. Miner Deposita 31: 539-547, 1996.

23. Dogan AU: Mesothelioma in Cappadocian villages. Indoor Built Env 12: 367-375, 2003.

24. Metintas M, Hillerdal G and Metintas S: Malignant mesothelioma due to environmental exposure to erionite: follow-up of a Turkish emigrant cohort. Eur Respir J 13: 523-526, 1999.

25. Roushdy-Hammady I, Siegel J, Emri S, et al: Genetic-susceptibility factor and malignant mesothelioma in the Cappadocian region of Turkey. Lancet 357: 444-445, 2001.

26. Boschmann KF, Burns PC, Hawthorne FC, et al: A-site disorder in synthetic fluor-edenite, a crystal-structure study. Can Mineral 32: 21-30, 1994

27. Eugene CJ and Arnold KJ: Study on synthetic fluor-tremolite, part 1 of synthetic asbestos investigations. Am Mineral 39: 537-548, 1954

28. Robert JL, Della Ventura G and Thauvin JL: The infrared $\mathrm{OH}$-stretching region of synthetic richterites in the system $\mathrm{Na}_{2} \mathrm{O}-\mathrm{K}_{2} \mathrm{O}-\mathrm{CaO}-\mathrm{MgO}-\mathrm{SiO}_{2}-\mathrm{H}_{2} \mathrm{O}-\mathrm{HF}$. Eur J Mineral 1: 203-212, 1989.

29. Laitakari A: Uber die Petrographie der kalksteingerstatten von Parainen (Pargas). Bulletin de la Commission Geologique de Finlande 54: 10, 1921

30. Moore JN and Kerrick DM: Equilibria in siliceous dolomites of the Alta aureole, Utah. Am J Sci 276: 502-524, 1976.
31. Kearns LE, Kite LE, Leavens PB and Nelen JA: Fluorine distribution in the hydrous silicate minerals of the Franklin Marble, Orange County, New York. Am Mineral 65: 557-562, 1980.

32. Makino K, Yamaguchi Y and Tomita K: Fluor edenite from the Ishigamiyama lava dome of the Kimpo volcano, Kumamoto, southwest Japan. GANKO 91: 419-423, 1996 (In Japanese).

33. DeNardo P, Bruni B, Paoletti L, et al: Pulmonary fibre burden in sheep living in the Biancavilla area (Sicily): preliminary results. Sci Total Environ 325: 51-58, 2004.

34. Rapisarda V, Rapisarda G, Vico GD, et al: Monitoring of fluoro-edenite fibre pollution through the study of sheep lymph nodes as a model of a biological indicator. Occup Environ Med 62: 656, 2005.

35. Kilburn KH, Powers D and Warshaw RH: Pulmonary effects of exposure to fine fibreglass: irregular opacities and small airways obstruction. Br J Ind Med 49: 714-720, 1992.

36. Albin M, Engholm G, Hallin N and Hagmar L: Impact of exposure to insulation wool on lung function and cough in Swedish construction workers. Occup Environ Med 55: 661-667, 1998

37. Sripaiboonkij P, Sripaiboonkij N,Phanprasit W and Jaakkola MS: Respiratory and skin health among glass microfiber production workers: a cross-sectional study. Environ Health 8: 36, 2009.

38. Pairon J,Laurent F, Rinaldo M, et al: Pleural plaques and the risk of pleural mesothelioma. J Natl Cancer Inst 105: 293-301, 2013.

39. Elshazley M, Shibata E, Hisanaga N, et al: Pleural plaque profiles on the chest radiographs and CT scans of asbestos-exposed Japanese construction workers. Ind Health 49: 626-633, 2011.

40. Metintas M, Metintas S, Hillerdal G, et al: Nonmalignant pleural lesions due to environmental exposure to asbestos: A field-based, cross-sectional study. Eur Respir J 26: 875-880, 2005.

41. Hillerdal G and Henderson DW: Asbestos, asbestosis, pleural plaques and lung cancer. Scand J Work Environ Health 23: 93-103, 1997.

42. Hillerdal G: Pleural plaques and risk for bronchial carcinoma and mesothelioma. A prospective study. Chest 105: 144-150, 1994.

43. Perticaroli P, Mengucci R, Carletti M, et al: Asbestos-related diseases in former asbestos-cement workers in Senigallia. Med Lav 104: 277-288, 2013 (In Italian).

44. American Thoracic Society: Diagnosis and initial management of nonmalignant diseases related to asbestos. Am J Respir Crit Care Med 170: 691-715, 2004.

45. Kamp DW and Weitzman SA: The molecular basis of asbestos induced lung injury. Thorax 54: 638-652, 1999.

46. Kamp DW: Asbestos-induced lung diseases: an update. Trans Res 153: 143-152, 2009.

47. Soffritti M, Minardi F, Bua L, et al: First experimental evidence of peritoneal and pleural mesotheliomas induced by fluoro-edenite fibres present in Etnean volcanic material from Biancavilla (Sicily, Italy). Eur J Oncol 9: 169-175, 2004.

48. Loreto C, Rapisarda V, Carnazza ML, et al: Fluoro-edenite fibres induce lung cell apoptosis: an in vivo study. Histol Histopathol 23: 319-326, 2008

49. Martinez G, Musumeci G, Loreto $C$ and Carnazza ML: Immunohistochemical changes in vulnerable rat brain regions after reversible global brain ischaemia. J Mol Histol 38: 295-302, 2007

50. Travaglione S, Bruni B, Falzano L, et al: Effects of the new-identified amphibole fluoro-edenite in lung epithelial cells. Toxicol In Vitro 17: 547-552, 2003

51. Cardile V, Renis M, Scifo C, et al: Behaviour of the new asbestos amphibole fluor-edenite in different lung cell systems. Int J Biochem Cell Biol 36: 849-860, 2004.

52. Ledda C, Rapisarda V, Bracci M, et al: Professional exposure to basaltic rock dust: assessment by the Vibrio fischeri ecotoxicological test. J Occup Med Toxicol 8: 23, 2013.

53. Chiappino G, Sebastien P and Todaro A: Atmospheric asbestos pollution in the urban environment: Milan, Casale Monferrato, Brescia, Ancona, Bologna and Florence. Med Lav 82: 424-438, 1991 (In Italian). 